\title{
Extracellular Signal-Regulated Protein Kinases (ERKs) and ERK Kinase (MEK) in Brain: Regional Distribution and Regulation by Chronic Morphine
}

\author{
Jordi Ortiz, ${ }^{1}$ Herbert W. Harris, ${ }^{1}$ Xavier Guitart, ${ }^{1, a}$ Rose Z. Terwilliger, ${ }^{1}$ John W. Haycock, ${ }^{2}$ and Eric J. Nestler ${ }^{1}$ \\ 'Laboratory of Molecular Psychiatry, Departments of Psychiatry and Pharmacology, Yale University School of Medicine \\ and Connecticut Mental Health Center, New Haven, Connecticut 06508 and ${ }^{2}$ Department of Biochemistry and Molecular \\ Biology, Louisiana State University Medical Center, New Orleans, Louisiana 70119
}

Quantitative blot immunolabeling techniques were used to determine the concentrations of ERK1 $(M, 44 \mathrm{kDa})$ and ERK2 ( $M, 42 \mathrm{kDa}$ ), the two major extracellular signal-regulated protein kinases, in different regions of rat brain. The aggregate ERK concentrations (ERK1 and ERK2) were relatively high in each of the brain regions studied, ranging from $\sim 0.35$ $\mathrm{ng} / \mu \mathrm{g}$ protein in cerebellum to $\sim 1.2 \mathrm{ng} / \mu \mathrm{g}$ protein in nucleus accumbens. However, differences in the regional distributions of ERK1 and ERK2 resulted in ratios of their relative abundance that differed by close to 10 -fold among the regions studied. The ratios of ERK1 protein to ERK2 protein varied along a rostral-caudal gradient from a low of 0.16 in frontal cortex to a high of 1.5 in pons/medulla. In hypotonic homogenates from regions at either extreme of the gradient, ERK1 and ERK2 were both found to be predominantly ( $>80 \%$ ) soluble. In subcellular fractions prepared from sucrose homogenates of frontal cortex and pons/medulla, both ERK1 and ERK2 were enriched in the synaptosomal and cytosolic fractions, whereas ERK2 was also enriched in the microsomal fraction. By contrast, in subfractions containing purified nuclei, levels of ERK1 and ERK2 were about one-third of those seen in homogenates and, in subfractions enriched in mitochondria, both ERK1 and ERK2 were barely detectable. The catalytic activity of the ERKs paralleled their protein levels in all of the brain regions except the hippocampus, in which the activity and phosphotyrosine content were disproportionately high. As a possible explanation for this apparent disparity, the regional distribution of ERK kinase (MEK), which phosphorylates and activates the ERKs, was also investigated. The levels of immunoreactivity of the $M_{r} 45 \mathrm{kDa}$ ERK kinase band differed by about threefold among the brain regions, with the highest levels being present in nucleus

\footnotetext{
Received Dec. 28, 1993; revised June 1, 1994; accepled Aug. 8, 1994.

This work was supported by USPHS Grants DA07359, DA08227, and DA00203 (to E.J.N.), by NS25134 and MH00967 (to J.W.H.), and by the Abraham Ribicoff Research Facilities, Connecticut Mental Health Center, State of Connecticut Department of Mental Health. This work was performed while J.O. and X.G. were recipients of Fulbright Fellowships of the Spanish Ministry of Education and Science.

Correspondence should be addressed to Dr. Eric J. Nestler, Laboratory of Molecular Psychiatry, Departments of Psychiatry and Pharmacology, Yale University School of Medicine and Connecticut Mental Health Center, 34 Park Street, New Haven, CT 06508.

a Present address: Departmento de Farmacologia, Laboratorios Dr. Esteve. S.A., Avvenida Mare de Deu de Montserrat 221, 08026 Barcelona, Spain.

Copyright (C) 1995 Society for Neuroscience $0270-6474 / 95 / 151285-13 \$ 05.00 / 0$
}

accumbens, hippocampus, substantia nigra, and caudate/ putamen. Therefore, a higher concentration of ERK kinase immunoreactivity did not appear to account for the disproportionate levels of ERK activity and phosphotyrosine content in the hippocampus. Potential regulation of ERK and ERK kinase levels was also investigated in rats subjected to chronic morphine treatment. ERK1 and ERK2 levels were increased selectively in locus coeruleus and caudate/putamen after chronic morphine treatment, whereas ERK kinase immunoreactivity remained unchanged in all of the brain regions analyzed. In summary, the regional differences in ERK and ERK kinase expression and the region-specific regulation of ERK expression suggest that ERK-related signaling may play an important role in CNS function and its adaptive responses.

IKey words: MAP kinase, MAP kinase kinase, hippocampus, substantia nigra, phosphotyrosine, opiates, locus coeruleus]

Extracellular signal-regulated protein kinases (ERKs, also referred to as mitogen-activated protein kinases or MAP kinases) are a recently identified family of protein serine/threonine kinases that occupy a pivotal position in intracellular signaling pathways mediating mitogen/growth factor effects. ERKs are homologous to the yeast protein kinases KSS1 and FUS3, which execute pheromone-triggered decisions regarding commitment of the cell to mating versus cell division. The ERKs, and their signaling pathways, exhibit several novel characteristics, and the experimental activity generated by their discovery has been explosive (for reviews, see Blenis, 1993; Crews and Erikson, 1993; Davis, 1993; Nishida and Gotoh, 1993).

The two most-studied ERKs are ERK1 $(M, 44 \mathrm{kDa})$ and ERK2 $\left(M_{r} 42 \mathrm{kDa}\right)$, while ERK3 $\left(M_{r} 63 \mathrm{kDa}\right)$ and other $M_{r}$ species remain less well-characterized. Activation of ERK 1 and ERK2 involves their phosphorylation on both a tyrosine and a neighboring threonine residue (see Robbins et al., 1993). This novel form of activation appears to be catalyzed specifically by an equally novel type of "dual function" protein kinase (see Rossomondo et al., 1992), referred to as ERK kinase or MEK, for MAP kinase/ERK kinase (Crews and Erikson, 1992), which is itself presently emerging as a distinct family of protein kinases (Seger et al., 1992; Otsu et al., 1993; Wu et al., 1993). Similarly, "dual function" protein phosphatases that specifically dephosphorylate ERKs in vitro have recently been discovered (Alessi 
et al., 1993; Zheng and Guan, 1993), and these may be responsible for ERK inactivation.

The wide range of extracellular signals capable of activating the ERKs (Cobb et al., 1991) belies the specificity of ERK phosphorylation by ERK kinase. In fact, at least three different protein kinase/signaling pathways appear to converge upon the ERKs via the Ser/Thr phosphorylation and activation of ERK kinase (see Pelech, 1993). In one pathway, growth factor signaling via their tyrosine kinase receptors leads to the association of the GTP-binding protein Ras with Raf-1, a protein Ser/Thr kinase, enabling Raf- 1 to phosphorylate and activate ERK kinase (e.g., Dent et al., 1992; Howe et al., 1992, Kyriakis et al., 1992). Extracellular signals acting through $G$ protein-coupled receptors may also activate $\mathrm{Raf}-1$, via a protein kinase $\mathrm{C}$ cascade. An alternative pathway thought to be stimulated by these receptors involves the activation of a recently cloned protein Ser/Thr kinase (Lange-Carter et al., 1993) that is immediately upstream of ERK kinase and has been termed, variously, MEK kinase, ERK kinase kinase, or MAP kinase kinase kinase (Gomez et al., 1992; Lange- Carter et al., 1993; Matsuda et al., 1993). Yet another putative activator of ERK kinase is the proto-oncogene product Mos, a protein Ser/Thr kinase, which has been shown to activate ERK via ERK kinase in frog oocytes (Posoda et al., 1993).

Downstream, the ERKs themselves phosphorylate a relatively distinct set of substrates, in which a proline residue immediately carboxyl to the Ser/Thr phosphoryl acceptor is required (see Davis, 1993). In mammalian cells, ribosomal S6 kinases and nuclear transcription factors such as c-Jun are thought to be substrates for the ERKs (see Blenis, 1993; Davis, 1993), consistent with an involvement of the ERKs in translating extracellular signals into alterations in gene expression (Pages et al., 1993).

ERKs are ubiquitously expressed in vertebrates, and the regulation of ERK phosphorylation and activity has been reported in numcrous ccll types from highly diverse origins. Similarly, in mammals, ERKs are widely distributed throughout the body; however, the highest levels of ERK mRNA are found in brain and spinal cord (Boulton et al., 1991), and the expression of ERK protein appears to parallel that of the mRNA (Boulton and Cobb, 1991). ERK-mediated phosphorylation of a specific substrate in a physiological context was, in fact, demonstrated first for a neuronal enzyme, tyrosine hydroxylase - the rate-limiting enzyme in catecholamine biosynthesis. In PC1 2 cells, ERK activation was shown to mediate the phosphorylation of serine31 in tyrosine hydroxylase that was produced by treatment of the cells with bradykinin (Haycock et al., 1992). Moreover, a body of evidence indicates that the phosphorylation and activation of ERKs is involved in several aspects of signaling in PC12 and other peripheral cells of neural crest origin. Numerous extracellular signals includirg secretagogues regulate ERK phosphorylation and activity in adrenal medullary chromaffin cells (Ely et al., 1990; Cahill and Perlman, 1991; Pavlovik-Surjancev et al., 1992; Haycock, 1993a), and the ERKs figure prominently in the actions of NGF on PC12 cells and peripheral neurons (Gotoh et al., 1990; Haycock et al., 1992; Qiu and Green, 1992; Scimeca et al., 1992; Traverse et al., 1992).

Despite the reported prevalence of ERKs in brain and spinal cord, exceedingly little attention has been paid to their distribution and potential regulatory influences in the brain. Indirect evidence, based on an increase in the phosphorylation of striatal tyrosine hydroxylase at serine- 31 produced by electrical stim- ulation of the nigrostriatal pathway (Haycock and Haycock, 1991), suggests that increased neuronal firing increases ERK activity. More recently, Baraban and coworkers have demonstrated directly that the activity and phosphotyrosine content of both ERK1 and ERK2 are increased in the hippocampus after seizure-producing electroconvulsive shock (Stratton et al., 1991; Baraban et al., 1993). Also, in isolated hippocampal neurons, ERK phosphorylation/activity is increased by epidermal growth factor treatment (Tucker et al., 1993) or glutamate receptor activation (Bading and Greenberg, 1991). Glutamate receptor activation also increases ERK phosphorylation/activity in primary cultures of cerebral cortical neurons (Fiore et al., 1993b).

Although such functional studies are relatively few in number, surprisingly, even less is known regarding the levels and distribution of ERKs in the CNS. Only one such study has appeared since the seminal observations by Cobb and coworkers regarding the relative abundance of ERKs in the CNS (Boulton and Cobb, 1991; Boulton et al., 1991). In this study, Schanen and Landreth (1992) reported that chromatographically isolated fractions of ERK activity from whole brain contained ERK I (but not ERK2) and only in very low abundance.

Thus, as a first step toward better understanding the potential role of ERKs and ERK-related signaling pathways in brain function, we undertook a detailed analysis of the regional distributions of ERK 1 and ERK2 in rat brain. In agreement with the original reports by Boulton et al. (1991), we found ERK1 and ERK2 to be relatively abundant in brain. We also found striking regional differences in the distributions of ERK1 and ERK2, and of ERK kinase, in the brain and present information on the subcellular distribution of the ERKs in nervous tissue. In addition, we addressed the possibility that levels of ERK expression, in addition to ERK phosphorylation, might be subject to regulation in the brain by examining the influence of chronic morphine administration on ERK immunoreactivity in selected brain regions. Chronic morphinc was chosen because it is known to produce adaptive changes in intracellular signaling proteins in specific target brain regions. We show here regional selectivity in the regulation of ERK levels in response to chronic morphine treatment.

\section{Materials and Methods}

\section{Materials}

Several anti-ERK peptide antibodies were used in the present study. Rabbit antibodies to peptide sequences from domain I (692), domain XI (691), and the C-terminal domain $(837,956)$ (Boulton et al., 1991) were gifts from Dr. M. H. Cobb (U. of Texas, Dallas) and Dr. N. G. Ahn (U. of Colorado, Boulder). Monoclonal mouse antibody to the C-terminal domain of ERKs was purchased from Zymed and GIBCO (clone MK12). Purified recombinant ERK (human ERK1, rat ERK2, and tyrosine- and threonine-phosphorylated rat ERK2) were generously provided by Drs. Ahn and Cobb.

A rabbit anti-ERK kinase antibody, raised against a peptide corresponding to the C-terminal domain of ERK kinase-1, was purchased from Santa Cruz Biotechnology (Santa Cruz, CA). A second rabbit antiERK kinase antibody, raised against the peptide FVGTSTYMSPERIC (from domain VIII of the yeast STE7 protein kinase), was purchased from UBI (06-200; Lake Placid, NY). Recombinant anti-phosphotyrosine antibody variable region $(\mathrm{RC} 20 \mathrm{H})$ was obtained from Transduction I abs (I exington, KY). Biotin-conjugated goat antiperoxidase and peroxidase-conjugated streptavidin were obtained from Jackson ImmunoResearch (West Grove, PA).

Unless indicated, sources for other reagents were as listed in the cited descriptions. 
Animals, treatments, and tissue preparation

Male Sprague-Dawley rats (150-200 gm; Camm, NJ) were maintained in standard housing on a $12 \mathrm{hr} / 12 \mathrm{hr}$ light/dark cycle (lights on, 7 A.M.). Animals were killed by decapitation, and their brains were removed and cooled briefly in chilled balanced salt solution $(126 \mathrm{mM} \mathrm{NaCl}, 5$ mм KCl, $1.25 \mathrm{~mm} \mathrm{NaH} \mathrm{PO}_{4}, 10 \mathrm{~mm}$ glucose, $25 \mathrm{~mm} \mathrm{NaHCO}_{3}, 2 \mathrm{~mm}$ $\left.\mathrm{CaCl}_{2}, 2 \mathrm{mM} \mathrm{MgSO}_{4}, \mathrm{pH} 7.4\right)$. Brain regions were dissected rapidly and, unless otherwise indicated, frozen on dry ice. The locus coeruleus, ventral tegmental area, dorsal raphe, substantia nigra, and nucleus accumbens were obtained as 12-15 gauge punches of coronal cross sections of brain as described previously (see Beitner-Johnson et al., 1992). The remaining brain regions and cervical sections of spinal cord were obtained by gross dissection.

In the chronic morphine experiments, each rat received one morphine pellet containing $75 \mathrm{mg}$ of morphine base (National Institute on Drug Abuse), implanted subcutaneously under light halothane anesthesia, daily for $5 \mathrm{~d}$ and the rats were killed on day 6 . This treatment elicits well-documented states of opiate tolerance and dependence in the rats on the basis of behavioral, electrophysiological, and biochemical observations (see Rasmussen et al., 1990; Nestler, 1992). Control rats underwent the same procedure but without pellet implantation.

Single electroconvulsive seizures were induced in rats as described previously (Nestler et al., 1989), and the animals were killed by decapitation, or perfused with formaldehyde and processed for immunohistochemistry (see below), 15 min later. Animals in the unstimulated, control group were treated identically with the exception of current delivery.

The distribution of ERKs in overall soluble versus particulate compartments was determined in total particulate $\left(\mathrm{P}_{\mathrm{T}}\right)$ and total soluble $\left(\mathrm{S}_{\mathrm{T}}\right)$ fractions (Nestler et al., 1989) from brain samples homogenized in icecold hypotonic buffer [ $20 \mathrm{~mm}$ Tris-HCl, pH 7.4, 2 mM EDTA, $1 \mathrm{~mm}$ dithiothreitol, 50 kallikrein U/ml aprotinin (Sigma), $10 \mu \mathrm{g} / \mathrm{ml}$ leupeptin (Sigma)]. The $\mathrm{P}_{\mathrm{T}}$ and $\mathrm{S}_{\mathrm{T}}$ fractions were separated by centrifugation $\left(150,000 \times g \times 15 \mathrm{~min} ; 4^{\circ} \mathrm{C}\right)$ in a Sorvall RCM100 micro-ultracentrifuge. After the protein content of the fractions was determined, aliquots containing equal amounts of protein were subjected to blot immunolabeling (see below). Classical subcellular fractions (Cotman et al., 1974) were prepared from freshly dissected, nonfrozen brain regions by standard methods (Nestler et al., 1989). Brain samples were homogenized in ice-cold isotonic sucrose $(0.32 \mathrm{M}$ with $5 \mathrm{~mm}$ Tris- $\mathrm{ICl}, \mathrm{pH} 7.4$ added) at 10-20 $\mathrm{mg}$ wet weight $/ \mathrm{ml}$ using Teflon/glass tissue grinders. Homogenates were centrifuged $\left(900 \times g \times 10 \mathrm{~min} ; 4^{\circ} \mathrm{C}\right)$ in a Tomy MTX-150 microcentrifuge, and the pellets were resuspended in fresh buffer and recentrifuged; the resulting pellets constituted the crude nuclear fraction $\left(P_{1}\right)$. The supernatants from the first centrifugation were spun at 9000 $\times g \times 10 \mathrm{~min}\left(4^{\circ} \mathrm{C}\right)$ in a microcentrifuge, and the pellets were resuspended in fresh buffer and recentrifuged; the resulting pellets constituted the crude synaptosomal fraction $\left(\mathrm{P}_{2}\right)$. The supernatants were centrifuged $\left(150,000 \times g \times 15 \mathrm{~min} ; 4^{\circ} \mathrm{C}\right)$ in a Sorvall micro-ultracentrifuge; the resulting pellets constituted the crude microsomal fraction $\left(\mathrm{P}_{3}\right)$ and the resulting supernatants constituted the cytosolic fraction $\left(S_{3}\right)$. In some experiments, nuclei were subfractionated from the $P_{1}$ fraction (Giuffrida et al., 1975) and free mitochondria were subfractionated from the $P_{2}$ fraction (Cotman et al., 1974). The protein content of subcellular fractions was determined, and aliquots (containing equal amounts of protein) were subjected to blot immunolabeling, as described below.

\section{Blot immunolabeling methods}

General procedure. Samples were solubilized in 1\% SDS, and protein concentrations were determined by the method of Lowry et al. (1951). Aliquots containing equal amounts of protein were subjected to SDSpolyacrylamide gel electrophoresis in slab gels using the buffers described by Laemmli (1970). Proteins in the resolving gels (containing $7.5 \%$ acrylamide, $0.4 \%$ bisacrylamide) were transferred electrophoretically $(6 \mathrm{~V} / \mathrm{cm})$ to nitrocellulose sheets for $3-4 \mathrm{hr}$ at room temperature in $2.4 \mathrm{gm} /$ liter Tris, $9 \mathrm{gm} / \mathrm{liter}$ glycine, $15 \%$ methanol. In some experiments, samples werc subjectcd to two-dimensional clectrophoresis cxactly as described (Beitner-Johnson et al., 1992) prior to transfer of the proteins to nitrocellulose.

Nitrocellulose sheets were air-dried and incubated for $2 \mathrm{hr}$ at room temperature in blocking buffer [phosphate-buffered saline $(140 \mathrm{~mm} \mathrm{NaCl}$, $10 \mathrm{~mm} \mathrm{Na} \cdot \mathrm{PO}_{4}, \mathrm{pH} 7.2$ ) containing $0.05 \%$ Tween 20 and $0.5 \%$ polyvinylpyrrolidone] (Haycock, 1993b) and then overnight at $4^{\circ} \mathrm{C}$ in blocking buffer containing primary antibody. The sheets were rinsed for $2 \mathrm{hr}$ in blocking buffer without polyvinylpyrrolidone and then incubated for $2 \mathrm{hr}$ at room temperature with either ${ }^{125} \mathrm{I}$-labeled or HRP-conjugated goat anti-rabbit antibody. The sheets were again rinsed $(2 \mathrm{hr}$, room temperature), and immunoreactivity was visualized using autoradiographic film [Kodak XAR-5 for ${ }^{125}$ I detection or Amersham Hyperfilm for detection of the peroxidase/enhanced chemiluminescence (ECL, Amersham) reaction product]. Immunoreactivity was quantified from the optical density of each band in arbitrary densitometric units by use of an image analysis system.

Immunolabeling and quantitation of ERKs. As a result of the considerable sequence homology between ERK1 and ERK2, antibodies raised against a peptide sequence from one of the ERKs will usually cross-react to some extent (depending upon the peptide sequence, immunological response, etc.) with the other ERK. For any given antiERK antibody (or combination of antibodies), regional differences in ERK1 (or ERK2) immunoreactivity will reflect regional differences in ERK1 (or ERK2) protein. In addition, regional differences in the ratio of ERK1 to ERK2 immunoreactivity will reflect regional differences in their relative abundances. However, because the relative intensity of ERK 1 versus ERK2 immunoreactivity will depend entirely upon the degree of cross-reactivity of the anti-ERK antibodies used, the actual numerical values of ERK 1 to ERK2 immunoreactivity ratios cannot be directly translated into ratios of ERK protein. This arbitrary difference in the intensity of ERK 1 versus ERK2 immunoreactivity can, however, be normalized by expressing the immunoreactivity of each ERK relative to that in a uniform tissue standard run on the same gel/nitrocellulose sheet; in the present studies, the hippocampus was used for this purpose. When normalized in this fashion, these values for ERK immunoreactivities can then be directly converted into amounts of ERK protein if the absolute levels of ERK protein in the tissue standard can be determined. Thus, the absolute levels of ERK1 and ERK2 in hippocampus (ng ERK/mg hippocampal protein) were determined (see below), allowing conversion of the levels of ERK1 and ERK2 immunoreactivity in various brain regions relative to hippocampal ERK1 and ERK2 levels into absolute units. This method of analysis not only provides quantitation of ERK1 and ERK2 protein in the different brain regions but allows the use of any particular anti-ERK antibody or mixture of antibodies by virtue of its independence of assumptions regarding antibody cross-reactivities.

Such normalization requires that levels of immunoreactivity fall either within a lincar portion of the ERK concentration-immunorcactivity curve or within the range of immunoreactivities of the hippocampal standard curve. For the antibody preparations and conditions used in the regional analyses, ERK1 and ERK2 immunoreactivities varied in an approximately linear fashion with hippocampal protein, over the range of $40-160 \mu \mathrm{g}$ of protein per lane when using ${ }^{125} \mathrm{I}$ detection and over the range of $10-40 \mu \mathrm{g}$ of protein per lane when using ECL detection.

Determination of ERK levels in a given brain region relative to ERK levels in hippocampus would appear to be the most reliable and valid method of standardization in such blot immunolabeling studies. This is because the compositions of samples subjected to immunolabeling (e.g., tissue type, tissue processing, salt concentrations, protein load) are relatively constant across brain regions. This is in contrast to the use of purified ERKs as standards, wherein several systematic errors could result (see below). For cxample, the absence of other protcins in the vicinity of the ERK bands could dramatically influence efficiency of transfer to nitrocellulose or binding of antibodies.

Immunolabeling of ERK kinase. The regional distribution of ERK kinase in rat brain was studied using affinity-purified polyclonal antibodies raised against peptide sequences of ERK kinases. Blot immunolabeling studies were carried out as described above, with the exception that $0.5 \%$ milk powder was substituted for polyvinylpyrrolidone in the blocking buffer. Two antibodies were used, both of which recognized a predominant single band of $\sim 45 \mathrm{kDa}$. However, several ERK kinases of this same mass have now been reported, and cross-reactivities of these antibodies with the different mammalian ERK kinases have not yet been fully documented. The anti-ERK kinase from Santa Cruz (directed against the C-terminus domain of ERK kinase-1) would not be expected to recognize ERK kinase-2 (Wu et al., 1993), but could conceivably recognize as yet undescribed forms of ERK kinase. The anti-ERK kinase from UBI is directed against a peptide common to ERK kinase-1 and-2 (see Wu et al., 1993). Thus, the ERK kinase immunoreactivity in the present studies may represent one or more ERK kinases. Levels of ERK kinase immunoreactivity varied in an approximately linear fashion with hippocampal protein over the range of 20$80 \mu \mathrm{g}$ of protein per lane using ECL detection. 


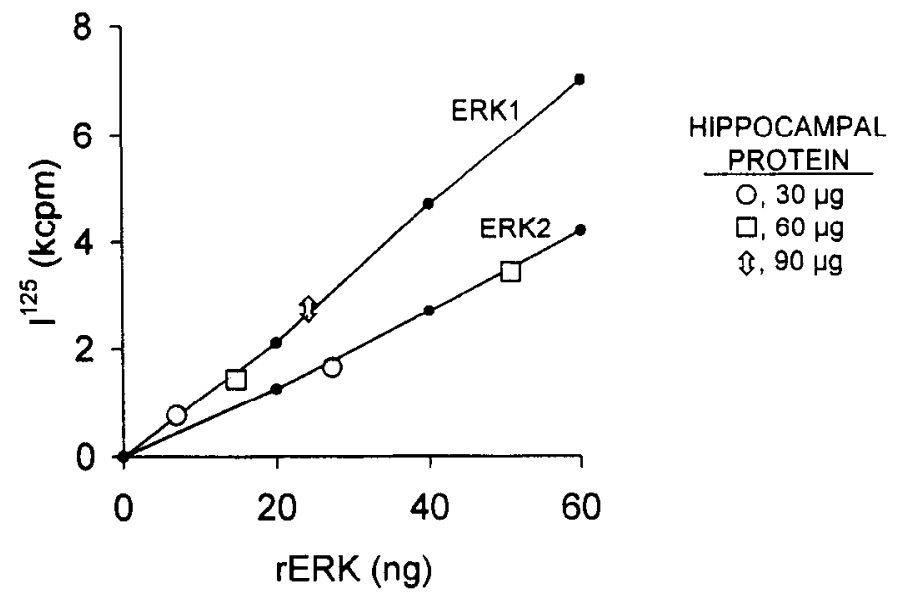

Figure 1. Calibration of ERK1 and ERK2 levels in the hippocampal tissue standard. Aliquots of SDS-solubilized, ERK-deficient, human kidney cortex containing the indicated amounts of purified, recombinant ERK1 and ERK2 (1 ng each $/ \mu \mathrm{g}$ kidney protein) and aliquots of SDSsolubilized rat hippocampus (containing 30,60 , or $90 \mu \mathrm{g}$ of protein) were subjected to SDS-polyacrylamide gel electrophoresis followed by electrophoretic transfer to nitrocellulose in a Genie blottcr (sec Materials and Methods). The sheets were then subjected to blot immunolabeling of ERKs (using the ${ }^{125}$ I detection method) and autoradiography. ERK immunoreactivity was quantitated by gamma counting of the ${ }^{125} \mathrm{I}-\mathrm{la}$ beled bands. The data in the figure present the results from one of three independent determinations and represent the medians from triplicate lanes.

Immunolabeling of phosphotyrosine. ERKs were immunoprecipitated (see below) from SDS-solubilized brain samples, subjected to SDSpolyacrylamide gel electrophoresis, and transferred to nitrocellulose using the quantitative transfer protocol described below. A recombinant anti-phosphotyrosine antibody $(\mathrm{RC} 20 \mathrm{H})$, composed of the variable regions of the mouse monoclonal anti-phosphotyrosine clone PY20 with mutations introduced to increase its affinity for phosphotyrosine approximately 10 -fold, was used as the primary antibody. However, despite the superior blot immunolabeling performance of this antibody, detection of phosphotyrosine in the ERK immunoprecipitates from unstimulated brain tissue was below the sensitivity of detection using the standard ECL protocol. Thus, after overnight incubation with the primary antibody $(0.5 \mu \mathrm{g} / \mathrm{ml})$ as described above, the nitrocellulose sheets were incubated sequentially at room temperature with biotinconjugated goat antiperoxidase $(1 \mathrm{hr}, 1 \mu \mathrm{g} / \mathrm{ml})$ and peroxidase-conjugated streptavidin $(1 \mathrm{hr}, 2 \mu \mathrm{g} / \mathrm{ml}$ ) prior to development of immunoreactivity with the ECL reagents.

Calibration of hippocampus tissue standard for ERK levels. Preliminary studies intended to validate recoveries of ERKs indicated that several different standard tank or semidry transfer protocols left a large proportion (up to 50\%) of ERK1 or ERK2 in the resolving gel. Although the addition of extraneous proteins (e.g., molecular weight standards or tissue extracts) to the lanes decreased the proportion of ERK retained in the gel, the degree of improvement depended upon the proteins added, and recoveries never exceeded $70 \%$. The use of a specialized tank transfer device capable of producing relatively high voltage fields (Genie Blotter with platinized titanium anode, $10 \mathrm{~V} / \mathrm{cm}$ for $2-3 \mathrm{hr}$; Idea Scientific, MN) dramatically improved recoveries. Purified ERKs were transferred with $\sim 80 \%$ efficiency and, in the presence of additional proteins, $85-90 \%$ recoveries were routinely obtained.

This transfer protocol was then used to calibrate the levels of EKKl and ERK2 in the working tissue standard (hippocampus pooled from three rats). As shown in Figure 1, the concentrations of ERK1 and ERK2 in the hippocampal sample were quantitated against standard curves of purified recombinant human ERK1 and rat ERK2 using 691 anti-ERK antibody (i.e., anti-KRITVEEALAHPYLEQYYDPTDE) as the primary antibody. Potential differences in transfer efficiencies were minimized by adding human kidney cortex extract (preadsorbed with immobilized anti-ERK) to the recombinant ERK lanes. Three determinations (in which replicates of multiple amounts of tissue and standards were run) were performed on separate days to provide the following concentrations of ERK 1 and ERK2 in the hippocampus: 0.27 $\mathrm{ng}$ of ERK 1 and $0.82 \mathrm{ng}$ of ERK 2 per $\mu \mathrm{g}$ of protein. The range of values from the three independent determinations was less than $20 \%$.

The peptide sequence against which the 691 antibodies were raised is identical in rat and human ERK1. Thus, the use of human ERK1 is unlikely to confound the calibration. However, the possibility that structural differences between the rat and human proteins elsewhere in the molecules could differentially influence immunoreactivity cannot be ruled out at present

\section{Immunoprecipitation of ERKs}

ERK1 and ERK2 were immunoprecipitated as described previously (Haycock, 1990) with minor modifications. Briefly, excess Nonidet P40 was added to SDS-solubilized samples, followed by immunoprecipitation buffer (Haycock, 1990) also containing (final concentrations) 100 $\mu \mathrm{M}$ vanadate and $100 \mathrm{nM}$ okadaic acid. Each sample was incubated for $1 \mathrm{hr}$ at room temperature with a mixture of anti-ERK antibodies (691, 837 , and MK 12 ); a mixture was found to be necessary to reliably obtain quantitative immunoprecipitation of both ERK 1 and ERK2. Incubation was continued for another $30 \mathrm{~min}$ after the addition of rabbit antimouse Ig and excess protein A-immunosorbent (Immunoprecipitin, BRL). Immunoglobulins and immune complexes were precipitated by centrifugation and resuspended by sonication directly in SDS-polyacrylamide sample buffer. Immunoprecipitation efficiencies were evaluated by blot immunolabeling analysis of small aliquots of each sample, taken before and after immunoprecipitation, in every experiment.

\section{ERK activity assay}

Samples (solubilized brain regions, immunoprecipitates, or activated rccombinant ERK2) wcre subjectcd to SDS-polyacrylamide gel clcctrophoresis in $1.5 \mathrm{~mm}$ slab gels (see above) containing $0.1 \mathrm{mg} / \mathrm{ml}$ myelin basic protein (Sigma), and phosphotransferase activity was measured in the gel after a cycle of denaturation and renaturation (PavlovicSurajancev et al., 1992). Briefly, after electrophoresis, gels were incubated sequentially in buffered isopropanol to remove SDS, $6 \mathrm{M}$ guanidine to denature the proteins, buffer containing 2-mercaptoethanol and Tween 20 to renature the proteins, a reaction mixture (25 mM HEPES, $10 \mathrm{~mm}$ $\mathrm{MgCl}_{2}, 2 \mathrm{mM} \mathrm{MnCl}, 5 \mathrm{~mm}$ 2-mercaptoethanol, $100 \mu \mathrm{M} \mathrm{Na}$ vanadate, $\left.10 \mu \mathrm{M} \gamma^{-32} \mathrm{P}-\mathrm{ATP}(20 \mu \mathrm{Ci} / \mathrm{ml}) ; 1 \mathrm{hr}, 32^{\circ} \mathrm{C}\right)$ to phosphorylate myelin basic protein, and $5 \%$ trichloroacetic acid, $10 \mathrm{~mm}$ sodium pyrophosphate to remove unincorporated ${ }^{32} \mathrm{P}$. Proteins were then stained with Coomassie $\mathrm{R} 250$, and the gels were dried and autoradiographed.

\section{Immunohistochemical analysis of ERK and ERK kinase}

Rats were deeply anesthetized by intraperitoneal injection of a $20 \%$ solution of chloral hydrate at a dose of $500 \mathrm{mg} / \mathrm{kg}$. Unconscious rats were perfused via the left ventricle with $4 \%$ formaldehyde in phosphatebuffered saline. Brains were then removed, postfixed in the same solution for 2-4 hr, and subsequently immersed in a cryoprotectant solution consisting of $15 \%$ sucrose, $0.05 \%$ sodium azide overnight. The brains were then dissected into $7 \mathrm{~mm}$ blocks, from which $40 \mu \mathrm{m}$ sections were cut on a sliding microtome.

Immunohistochemical staining was carried out as described (Hsu et al., 1981) with minor modifications. Briefly, free-floating brain sections were incubated in phosphate-buffered saline containing $0.3 \%$ Triton $\mathrm{X}-100,0.5 \%$ normal goat serum, and antibody at various dilutions on a rotating shaker for $16 \mathrm{hr}$ at $4^{\circ} \mathrm{C}$. The sections were then washed in phosphate-buffered saline and incubated for $60 \mathrm{~min}$ at room temperature with biotinylated anti-rabbit antibody (Vestastain ABC Kit, Vector Laboratories, Burlingame, CA) following the manufacturer's instructions. The sections were washed in phosphate-buffered saline and incubated for $60 \mathrm{~min}$ at room temperature with avidin-conjugated horseradish peroxidase. After final washes in phosphate-buffered saline, peroxidase activity was revealed by incubation of the sections with 0.5 $\mathrm{mg} / \mathrm{ml}$ diaminobenzidine (Sigma, St. Louis, MO) in $0.1 \mathrm{M}$ sodium acetate, $\mathrm{pH} 6.0,10 \mu \mathrm{g} / \mathrm{ml}$ glucose oxidase, $2 \mathrm{mg} / \mathrm{ml} \beta$-D-glucose. Sections were then mounted on microscope slides, dehydrated in graded alcohol solutions, cleared in Histoclear (Fisher, Pittsburgh, PA), and coverslipped. The slides were examined by bright-field microscopy with a Zeiss Axioscope. The following primary antibodies were used: affinitypurified 691 and serum 837 anti-ERK antibodies, and anti-ERK kinase antibodies from Santa Cruz and UBI (see Materials). 

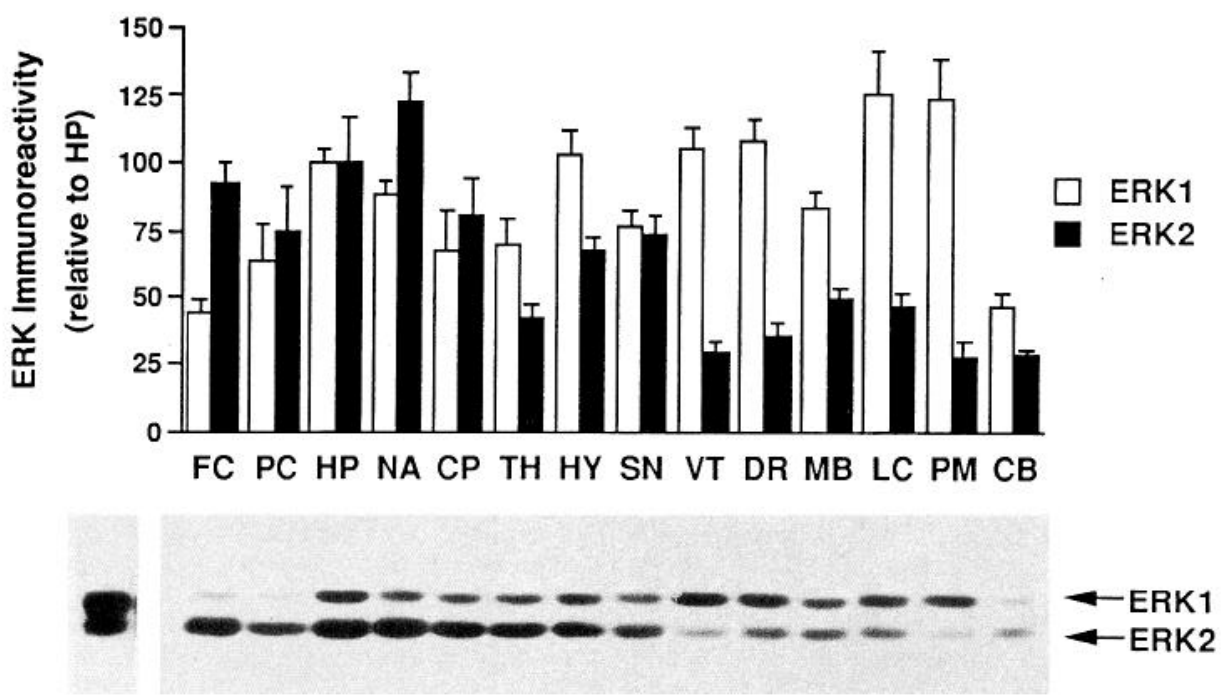

Figure 2. Regional distribution of ERK1 and ERK2 in rat brain. Aliquots (20 $\mu \mathrm{g}$ of protein) of SDS-solubilized extracts were subjected to SDS-polyacrylamide gel electrophoresis, and resulting gels were processed for blot immunolabeling of ERKs using 691 anti-ERK antibody as described in Materials and Methods. The upper panel summarizes the data (mean \pm SEM) obtained from four animals. $F C$, frontal cortex; $P C$, parietal cortex; $H P$, hippocampus; $N A$, nucleus accumbens; $C P$, caudate/putamen; $T H$, thalamus; $H Y$, hypothalamus; $S N$, substantia nigra: $V T$, ventral tegmental area; $D R$, dorsal raphe; $M B$, midbrain; $L C$, locus coeruleus; $P M$, pons/medulla; $C B$, cerebellum. The lower panel shows portions of resulting immunoblots (using the chemiluminescence detection method) obtained from a representative rat. Equal amounts of recombinant human ERK 1 and rat ERK2 were also run (left lane) for $M_{r}$ comparison.

\section{Results}

Regional distribution of ERK1 and ERK2

Figure 2 presents a summary of ERK1 and ERK2 immunoreactivity in 14 areas of rat brain as determined by blot immunolabeling analyses using the 691 anti-ERK as the primary antibody. An autoradiogram showing the data from a single rat and the immunoreactivity of equal amounts of recombinant ERK1 and ERK2 is also presented. The figure serves to illustrate the type of raw data collected in these studies before conversion of the immunoreactivity values into either absolute ERK levels or ratios of ERK immunoreactivities, both of which are presented in Table 1. Similar results were obtained using a mixture of 691,692 , and 837 anti-ERK antibodies, which produced a greater relative immunoreactivity of ERK2 than the 691 antibody alone (e.g., compare Fig. $6 \mathrm{~A}$ to Fig. 2). Although the ratios of ERK1 to ERK2 immunoreactivity were all lower using this antibody mixture, the same relative regional differences in ERK1 and ERK2 immunoreactivity were observed. Moreover, after normalization to hippocampal ERK immunoreactivities and conversion to absolute levels of ERK1 and ERK2, the values of ERKs in several brain regions (frontal cortex, nucleus accumbens, caudate/putamen, and pons/medulla) obtained with the mixture of 691, 692, and 837 anti-ERK antibodies were essentially identical to those obtained with the 691 antibodies alone.

As shown in Figure 2 and Table 1, total ERK (ERK1 plus ERK2) levels in brain ranged from a high of $1.25 \mathrm{ng} / \mu \mathrm{g}$ protein in nucleus accumbens to a low of $0.35 \mathrm{ng} / \mu \mathrm{g}$ protein in cerebellum. Moreover, the relative abundances of ERK1 versus ERK2 differed by close to 10 -fold among the regions studied. The ratio ERK1 to ERK2 levels varied in a rostral-caudal fashion from low to high, with the lowest ratio $(0.16)$ in frontal cortex and the highest ratio (1.5) in pons/medulla.

The rostral-caudal gradient of the relative distribution of ERK1

Table 1. Distribution of ERK1 and ERK2 in regions of rat brain

ng ERK/mg protein

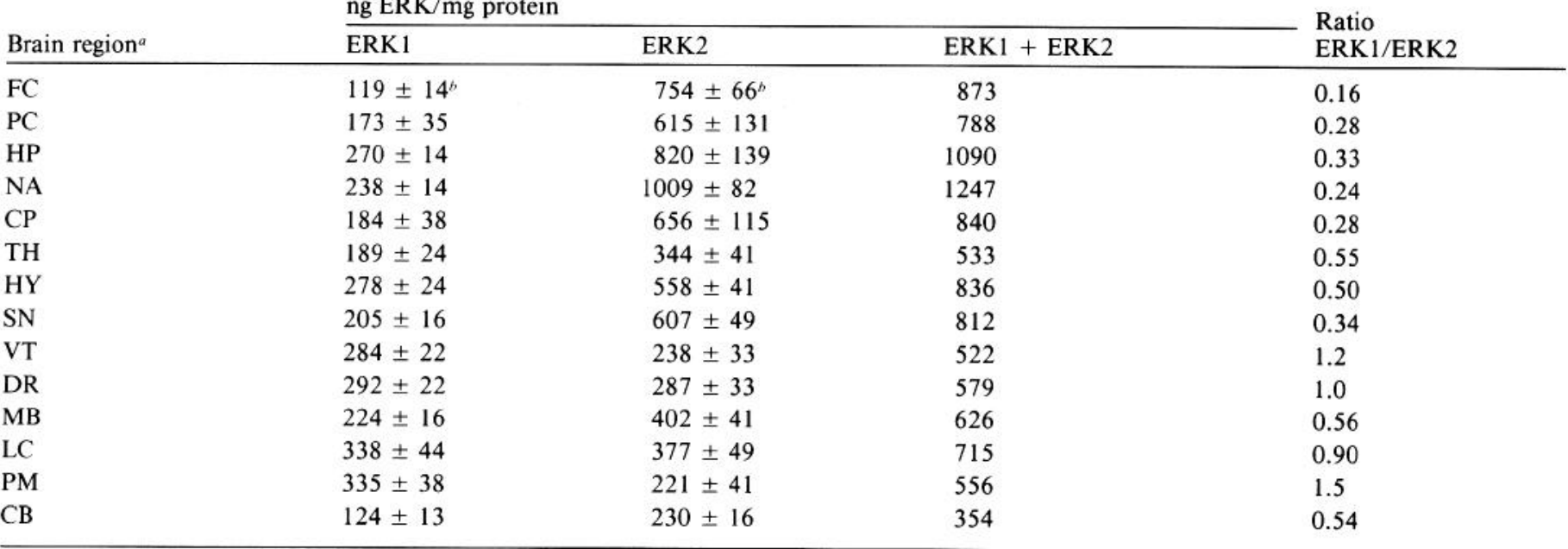

\footnotetext{
"See Figure 2 caption for abbreviations.
}

Mean $\pm \operatorname{SEM}(N=4)$. 


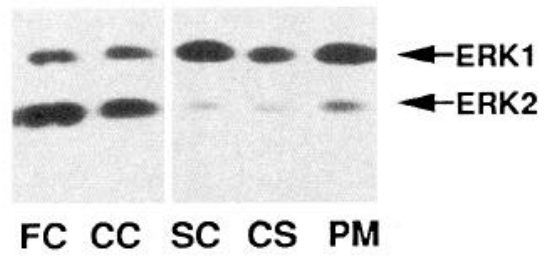

Figure 3. Autoradiogram showing the distribution of ERK1 and ERK2 in various regions of the CNS. Aliquots ( $20 \mu \mathrm{g}$ of protein) of SDSsolubilized extracts were subjected to SDS-polyacrylamide gel electrophoresis, and resulting gels were processed for blot immunolabeling of ERKs using 691 anti-ERK antibody and the chemiluminescence detection method as described in Materials and Methods. The results shown in the figure are representative of determinations derived from analyses of three rats. $F C$, frontal cortex; $C C$, corpus callosum; $S C$, spinal cord; $C S$, pontine corticospinal tract; $P M$, pons/medulla.

to ERK 2 in brain suggested two possible underlying factors. The regional differences could reflect rostral to caudal differences either in the neuronal distribution of the ERKs or in the distribution of the ERKs in gray versus white matter, given the higher levels of white matter present in some of the hindbrain dissections. For example, the pons/medulla would be expected to contain more white matter than frontal cortex. Arguing against the latter possibility is the fact that some of the hindbrain regions with high ERK1 to ERK2 ratios (e.g., ventral tegmental area, dorsal raphe, and locus coeruleus) do not contain a large proportion of white matter. However, to further address this possibility, we compared ERK levels in frontal cortex and pons/ medulla to levels in spinal cord, corpus callosum (an example of forebrain white matter), and the corticospinal tract in the pons (an example of pontine white matter). As shown in Figure 3 , corpus callosum showed relatively low levels of ERK1, similar to those seen in frontal cortex, whereas levels of ERK2 were somewhat lower than in frontal cortex. In contrast, spinal cord and the pontine corticospinal tract showed relatively high levels of ERK1, similar to those seen in pons/medulla, but even lower levels of ERK2. These results indicate that while there may be some variation in ERK (particularly ERK2) levels based on white matter content, most of the regional variation in ERK levels followed a rostral-to-caudal axis per se.

As shown in Figure 2, the anti-ERK antibodies reacted with an upper $44 \mathrm{kDa}$ band and a lower $42 \mathrm{kDa}$ band, which comigrated, respectively, with recombinant human ERK1 and recombinant rat ERK2. Several lines of evidence support the conclusion that the differences in immunoreactivity of the two bands reflected differences in amounts of protein in the immunoblots under the blot immunolabeling conditions used. First, the ratios of ERK1 to ERK2 immunoreactivity in a given brain region were constant over a relatively broad range of protein loads, and the relative ordering of ratios across brain regions did not change, using different combinations of antibodies. Second, levels of ERK1 and ERK2 in mixtures of tissues from two areas having disparate ratios (i.e., frontal cortex and pons/medulla) were predicted by the simple average of the two (data not shown). Third, the absolute levels of ERK1 and ERK2 determined with antibodies to different portions of the ERK molecules were essentially identical.

These same considerations also support the view that the two bands of ERK immunoreactivity observed in this study were derived from only two proteins, presumably ERK1 and ERK2.

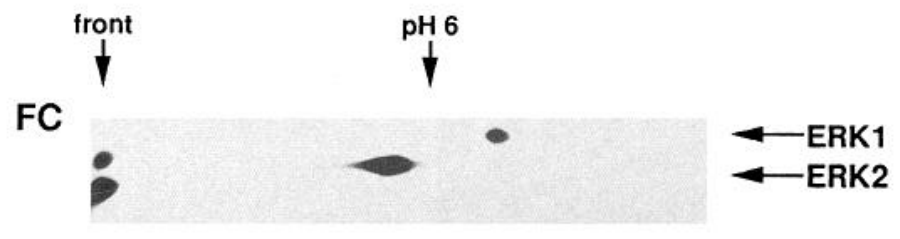

PM

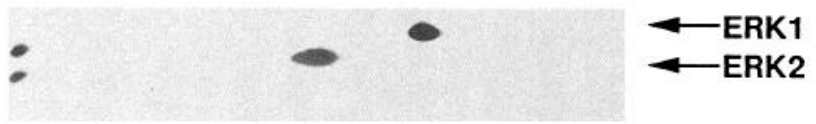

Figure 4. Autoradiograms showing ERK immunoreactivity after twodimensional electrophoretic separation. Aliquots ( $80 \mu \mathrm{g}$ of protein) of SDS-solubilized extracts of frontal cortex $(F C)$ and pons/medulla $(P M)$ were subjected to two-dimensional gel electrophoresis, and resulting gels were processed for blot immunolabeling of ERKs using a mixture of 691,692 , and 837 anti-ERK antibodies as described in Materials and Methods. Portions of autoradiograms of resulting two-dimensional immunoblots (using the chemiluminescence detection method) are shown. A portion of ERK 1 and ERK2, which apparently did not migrate through the first dimensional gel, is apparent toward the left-hand side of the autoradiograms. The apparent pIs of ERK1 and ERK2 derived from this two-dimensional electrophoretic analysis are more acidic than values reported previously ( $\sim 6.8$; Rossomando et al., 1989).

Additional, direct experimental support for this view is illustrated in Figure 4, in which blot immunolabeling analysis of solubilized frontal cortex and pons/medulla after two-dimensional electrophoresis identified only two immunoreactive species (with approximate pIs of 5.8 for ERK1 and 6.15 for ERK2). Moreover, the ratios of immunoreactivity of these two species were identical to those of the two bands after separation in one dimension.

It should be pointed out that the mixture of 691,692 , and 837 anti-ERK antibodies, in addition to recognizing ERK1 and ERK2, labeled a protein migrating just above ERK1 (at about $45 \mathrm{kDa}$ ) that was particularly enriched in pons/medulla (see Fig. $6 A$ ). This protein could represent ERK4, identified by Boulton and Cobb (1991) as a $45 \mathrm{kDa}$ protein recognized by certain antiERK antibodies in certain cultured cell lines and expressed in these lines at markedly different levels. However, independent verification is clearly needed to identify the $45 \mathrm{kDa}$ pons/medulla-enriched protein, recognized by anti-ERK antibodies, as ERK4.

\section{Subcellular distribution of ERK1 and ERK2}

In the total particulate and total soluble fractions prepared from hypotonic homogenates of frontal cortex and pons/medulla, $>80 \%$ of both ERKs was present in the soluble fractions from either brain region (data not shown), consistent with prior reports that the ERKs are not membrane-associated proteins (e.g., Boulton and Cobb, 1991). The distributions of ERKs in different cellular compartments were determined by blot immunolabeling analyses of subcellular fractions prepared from sucrose homogenates of frontal cortex and pons/medulla. As shown in Figure 5, the concentrations of ERK1 and ERK2 in frontal cortex were both lower in the $\mathrm{P}_{1}$ fraction than in the homogenate, whereas both ERK1 and ERK2 were enriched in the $P_{2}$ and $S_{3}$ fractions. By contrast, ERK2 but not ERK1 was enriched in the $\mathrm{P}_{3}$ fraction. Equivalent relative distributions were observed for subcellular fractions from pons/medulla (data not shown).

The $\mathrm{P}_{1}$ fraction was subfractionated in order to determine the levels of ERKs associated specifically with nuclei. Both ERK1 


\section{Relative ERK levels}

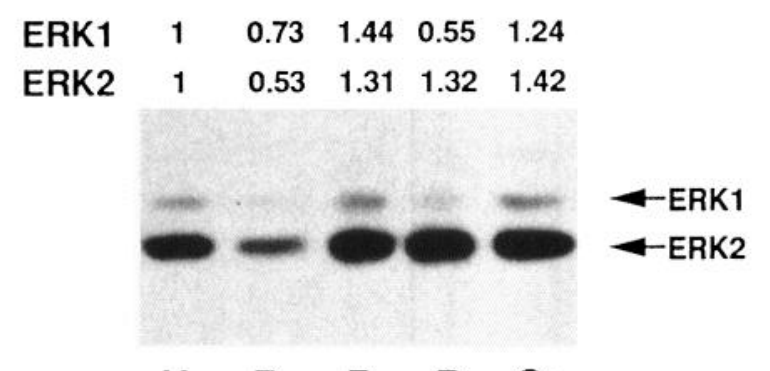

\section{$\begin{array}{lllll}H & P_{1} & P_{2} & P_{3} & S_{3}\end{array}$}

Figure 5. Autoradiogram showing the subcellular distribution of ERK1 and ERK2 in frontal cortex. The indicated subcellular fractions were prepared from homogenates of frontal cortex (see Materials and Methods). Aliquots ( $80 \mu \mathrm{g}$ of protein) of the fractions were then subjected to SDS-polyacrylamide gel electrophoresis and to blot immunolabeling of ERKs using 691 anti-ERK antibody ('25 I detection method) as described in Materials and Methods. The amount of ERK protein per microgram of total protein in each subcellular fraction is expressed relative to that in homogenates. The values summarize the results from four separate fractionations, each using frontal cortex from one rat. A representative autoradiogram is shown. $P_{1}$, crude nuclear fraction; $P_{2}$, crude synaptosomal fraction; $P_{3}$, crude microsomal fraction; $S_{3}$, cytosolic fraction.

and ERK2 were present at relatively low levels in a more highly purified nuclear fraction prepared from $\mathrm{P}_{1}$ according to Giuffrida et al. (1975). As estimated by extrapolation from the tissue standard curve, the specific activities of ERK1 and ERK2 in purified nuclei were, respectively, $29 \pm 7 \%$ and $31 \pm 6 \%$ (mean $\pm \mathrm{SEM} ; N=4$ ) of those in the homogenate. Moreover, given that only a small fraction of all cellular protein is associated with the nucleus, these results indicate that a minute percentage of total cellular ERK is present in the nuclear compartment in brain. To test the possibility that the ERKs might become associated with the nuclear fraction only under conditions of enzyme activation, we studied ERK levels in purified nuclear fractions of hippocampus of animals after an acute electroconvulsive seizure, a condition shown previously to activate ERKs (Baraban et al., 1993). It was found that an acute seizure did not increase levels of ERK1 or ERK2 in nuclear fractions $15 \mathrm{~min}$ postseizure (data not shown).

The $\mathrm{P}_{2}$ fraction, composed primarily of synaptosomes and free mitochondria, was also subfractionated in order to determine the levels of ERKs associated specifically with free mitochondria. Both ERK1 and ERK2 were barely detectable in a purified mitochondrial fraction prepared from $\mathrm{P}_{2}$ according to Cotman et al. (1974). Mitochondrial levels of ERK1 and ERK2 were estimated by extrapolation to be at least 10 -fold lower than in the homogenate.

\section{Comparison of ERK activity and phosphotyrosine content to ERK protein levels}

As stated in the introductory remarks, ERK1 and ERK2 are activated by the phosphorylation of neighboring tyrosine and threonine residues. Thus, the levels of ERK activity and phosphotyrosine content were compared to the levels of ERK protein in five representative brain regions (frontal cortex, hippocampus, nucleus accumbens, caudate/putamen, and pons/medulla). In these experiments, ERK1 and ERK2 were immunoprecipitated from extracts of the brain regions of naive rats as described in Materials and Methods, and aliquots of the extracts and immunoprecipitates were subjected to one-dimensional SDS-
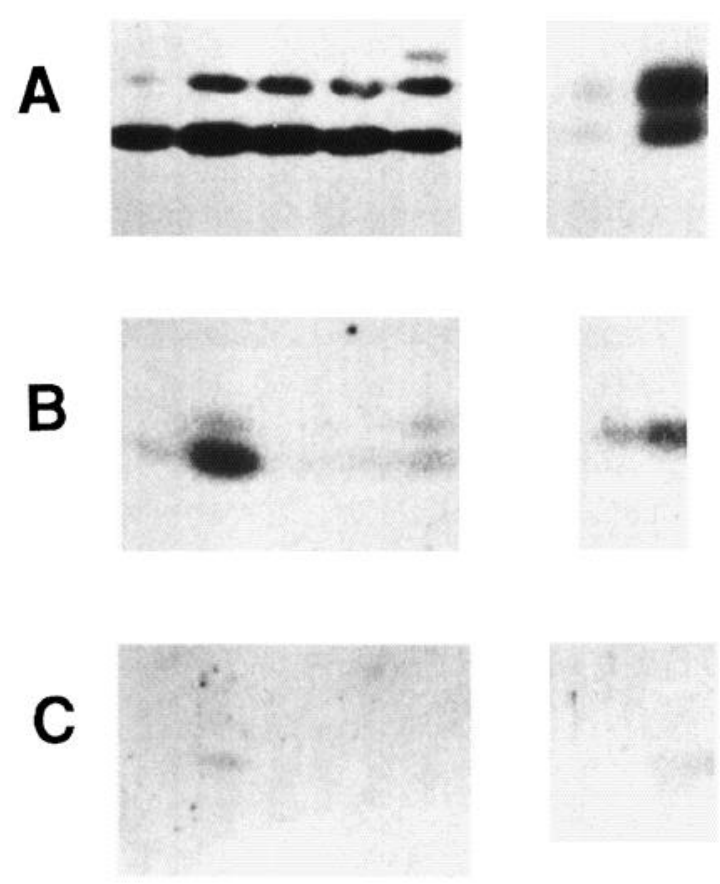

\section{FC HP NACP PM}

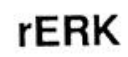

Figure 6. Autoradiograms showing ERK protein, enzyme activity, and phosphotyrosine content in rat brain regions. A, Aliquots $(20 \mu \mathrm{g}$ of protein) of SDS-solubilized extracts were analyzed by blot immunolabeling of ERKs using a mixture of 691,692 , and 837 anti-ERK antibodies (chemiluminescence detection method) as described in Materials and Methods. $B$, Aliquots ( $50 \mu \mathrm{g}$ of protein) of SDS-solubilized extracts were subjected to ERK immunoprecipitation, and resulting immunoprecipitates were subjected to SDS-polyacrylamide gel electrophoresis and analyzed for ERK catalytic activity (with myelin basic protein as a substrate) as described in Materials and Methods. $C$, Aliquots (50 $\mu \mathrm{g}$ of protein) of SDS-solubilized extracts were subjected to ERK immunoprecipitation, and resulting immunoprecipitates were subjected to SDS-polyacrylamide gel electrophoresis and analyzed by blot immunolabeling of phosphotyrosine as described in Materials and Methods. The results shown in the figure are representative of determinations derived from analysis of three rats. ERK blot immunolabeling, ERK activity, and phosphotyrosine blot immunolabeling analysis of 5 and $15 \mathrm{ng}$ of recombinant human ERK 1 and rat ERK2 $(A)$ or of 1 and 3 ng of recombinant activated rat ERK2 $(B$ and $C)$ are shown for comparison $(r E R K)$. Note that activated rERK 2 migrates just above ERK2 present in brain extracts $(B$ and $C$ ). See Figure 2 caption for brain region abbreviations.

polyacrylamide gel electrophoresis. ERK protein levels and phosphotyrosine content were analyzed by blot immunolabeling procedures, and ERK activity was analyzed according to Pavlovic-Surjancev et al. (1992) by measuring the incorporation of ${ }^{32} \mathrm{P}$ (from $\gamma^{32} \mathrm{P}-\mathrm{ATP}$ ) into myelin basic protein (an efficient in vitro substrate for the ERKs) that was precast into the SDSpolyacrylamide gels, as described under Materials and Methods. The levels of ERK immunoreactivity in the five brain regions are shown in Figure $6 \mathrm{~A}$, while the kinase activity toward myelin basic protein and the phosphotyrosine content of the immunoprecipitated ERKs are shown in Figure 5, $B$ and $C$, respectively.

In general, the ratios of ERK1 and ERK2 activity in the different brain regions (Fig. $6 B$ ) paralleled the regional differences in the ratios of ERK1 to ERK2 protein levels (Fig. 6A). For example, the activity of ERK2 was much greater than that 

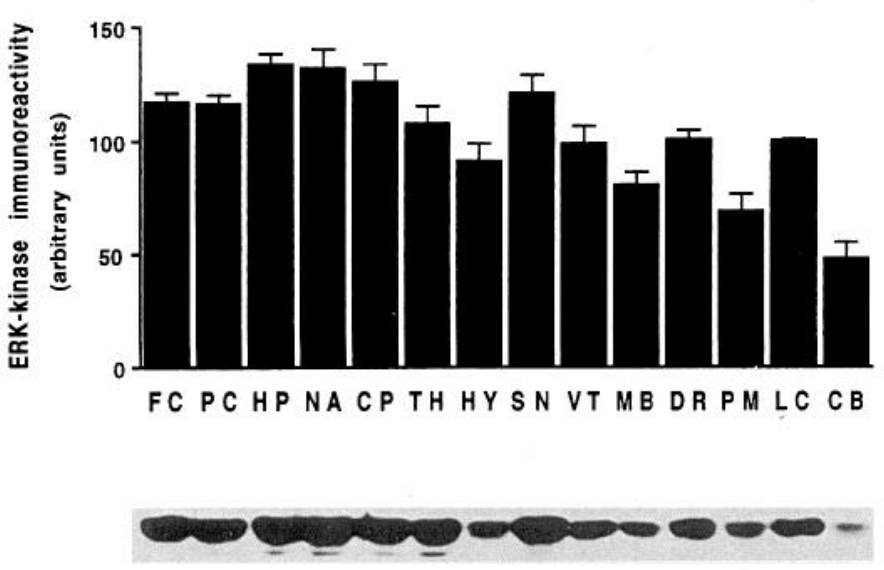

Figure 7. Regional distribution of ERK kinase in rat brain. Aliquots $(60 \mu \mathrm{g}$ of protein) of SDS-solubilized extracts were subjected to SDSpolyacrylamide gel electrophoresis, and resulting gels were processed for blot immunolabeling of ERK kinase using affinity-purified antibodies (from Santa Cruz) (chemiluminescence detection method) as described in Materials and Methods. The upper panel shows data obtained from three animals, expressed as mean \pm SEM. See Figure 2 caption for brain region abbreviations. The lower panel shows an autoradiogram of a representative immunoblot obtained from one rat. Note that in addition to the major $M_{r} 45 \mathrm{kDa}$ band, a minor band migrating just below it was evident in some brain regions. The identity of this minor band is unknown, but it generally occurs at levels that parallel those of the $45 \mathrm{kDa}$ protein.

of ERK1 in the forebrain regions, consistent with the higher levels of ERK2 protein (see Table 1), whereas the activities of ERK1 and ERK2 were more equivalent in pons/medulla, as were ERK1 and ERK2 protein. However, the levels of ERK activity in the hippocampus were disproportionately higher overall compared to those in the other brain regions. In fact, as shown in Figure $6 C$, phosphotyrosine was detectable only in the hippocampus sample, and only for ERK2. These results demonstrated that while the levels of ERK activity and phosphotyrosine generally followed one another, relative to ERK protein, they were much higher in the hippocampus.

\section{Regional distribution of ERK kinase}

A possible explanation for the higher activity and phosphotyrosine content of the ERKs in hippocampus compared to the other forebrain regions was that the hippocampus might contain higher levels of ERK kinase. Therefore, we also investigated the regional distribution of ERK kinase by blot immunolabeling procedures, using two different anti-ERK kinase antibodies. As shown in Figure 7 , there were clear regional differences $(\sim 3-$ fold) in the levels of ERK kinase immunoreactivity $\left(M_{r} 45 \mathrm{kDa}\right)$ with antibodies raised against a $\mathrm{C}$-terminal peptide sequence from ERK kinase-1. The highest levels of ERK kinase immunoreactivity were present in nucleus accumbens, hippocampus, substantia nigra, and caudate/putamen, with the lowest levels observed in cerebellum and pons/medulla. Spinal cord contained still lower levels of ERK kinase immunoreactivity (not shown). The use of a second ERK kinase antibody, directed against a peptide sequence from yeast ERK kinase, also labeled a single $45 \mathrm{kDa}$ band and resulted in a similar relative ordering of ERK kinase immunoreactivity among the brain regions studied, although the range of regional differences in ERK kinase levels was greater with this antibody (data not shown). The results with either antibody indicated that the unexpectedly high levels of ERK activity and phosphotyrosine content in the hippocampus relative to frontal cortex, nucleus accumbens, and caudate/putamen (as illustrated in Fig. 6) could not be explained simply on the basis of regional differences in ERK kinase levels.

\section{Localization of ERK and ERK kinase by immunohistochemistry}

To gain more information concerning the cellular localization of the ERKs and ERK kinase in brain, we studied the distribution of these proteins by immunohistochemical procedures using affinity-purified 691 anti-ERK and anti-ERK kinase (UBI) antibodies (see Materials and Methods). In general, the staining pattern of ERK and ERK kinase immunoreactivity was similar. The immunoreactivity with either antibody was associated principally with neuropil. Very few cell bodies exhibited distinct staining at any level of the neuraxis that was examined. Data for selected brain areas are shown in Figure 8. At the level of the midbrain, particularly high levels of ERK kinase-like immunoreactivity were observed in pars reticulata of the substantia nigra (Fig. $8 b$ ), consistent with the high levels of the enzyme detected in blot immunolabeling studies. Levels of ERK-like immunoreactivity were also enriched but to a lesser extent (Fig. $8 a$ ). At a more rostral level, high levels of ERK-like and ERK kinase-like immunoreactivity were found in hippocampus (Fig. $8 c, d$ ), where both antibodies produced similar, laminar distributions (Fig. $8 c-f$ ). Similar patterns of ERK-like and ERK kinase-like immunoreactivity were also observed when different antibodies (837 anti-ERK and Santa Cruz anti-ERK kinase) were used (data not shown). It should be noted that no significant nuclear staining was observed for the ERKs in the hippocampus either under basal conditions or $15 \mathrm{~min}$ after a single electroconvulsive seizure (data not shown).

\section{Regulation of ERK and ERK kinase by chronic morphine administration}

While the phosphorylation/activation of ERKs and ERK kinase are known to be highly regulated, little attention has been given to possible longer-term regulation, for example, the total amounts of these proteins. To gain a preliminary sense of whether the total amounts of ERKs and ERK kinase are subject to regulation in the brain, we studied the influence of chronic morphine administration on the levels of these proteins. Morphine was selected as a treatment, based on the increasing evidence that longterm exposure to morphine alters the levels of numerous signal transduction proteins in specific regions of the CNS (see Nestler, 1992; Nestler et al., 1993).

Rats were treated with morphine under conditions, described in Materials and Methods, known to elicit high levels of tolerance and dependence. As shown in Figure $9 A$, chronic morphine treatment increased the levels of both ERK1 and ERK2 in the locus coeruleus and caudate/putamen by $20-30 \%$. In contrast, no significant effects of morphine were observed on ERK levels in the other brain areas studied (substantia nigra, ventral tegmental area, nucleus accumbens, and frontal cortex). Moreover, chronic morphine treatment failed to influence the levels of ERK kinase immunoreactivity in any of the brain regions studied (Fig. 9B).

\section{Discussion}

The present study has shown that ERK1 and ERK2, the two major isoforms of ERK, have different regional distributions in 

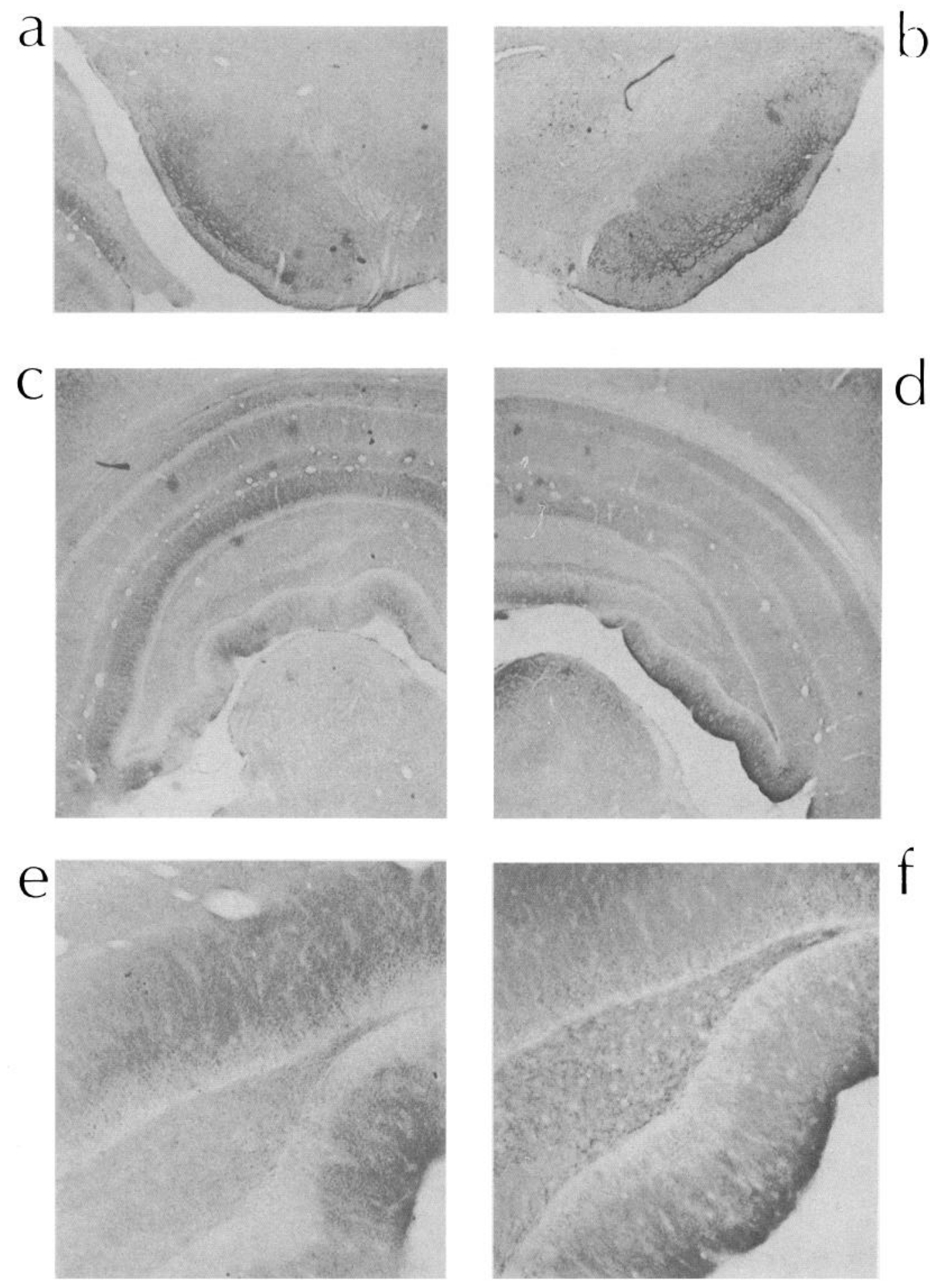

Figure 8. Immunohistochemical localization of ERK and ERK kinase in rat brain. Coronal sections of rat brain were analyzed for ERK-like $(a, c, e)$ or ERK kinase-like $(b, d, f)$ immunoreactivity as described in Materials and Methods using affinity purified 691 anti-ERK or anti-ERK kinase (UBI) antibodies. $a$ and $b$ show coronal sections through the ventral midbrain at the level of the substantia nigra and ventral tegmental area at low-power magnification. $c$ and $d$ show coronal sections through a caudal section of hippocampus at low-power magnification. $e$ and $f$ show coronal sections through the rostral hippocampus at higher-power magnification. Note the particular enrichment of ERK kinase-like immunoreactivity in the pars reticulata of the substantia nigra $(b)$. Note also the lack of cell body staining for both proteins in all of the sections shown, and the very similar laminar distributions of ERK-like and ERK kinase-like immunoreactivity in the hippocampus $(c-f)$.

the brain. While ERK immunoreactivity is widely distributed in the brain, specific brain areas differed by up to 3.5 -fold in the total levels of ERK immunoreactivity, and even more so in the relative abundance of ERK1 and ERK2, which differed by close to an order of magnitude among the brain regions studied. In the brain, the frontal cortex had the lowest ERK1-to-ERK2 ratio and pons/medulla had the highest, while the ratio in spinal cord was even higher than that in pons/medulla. The distri- 

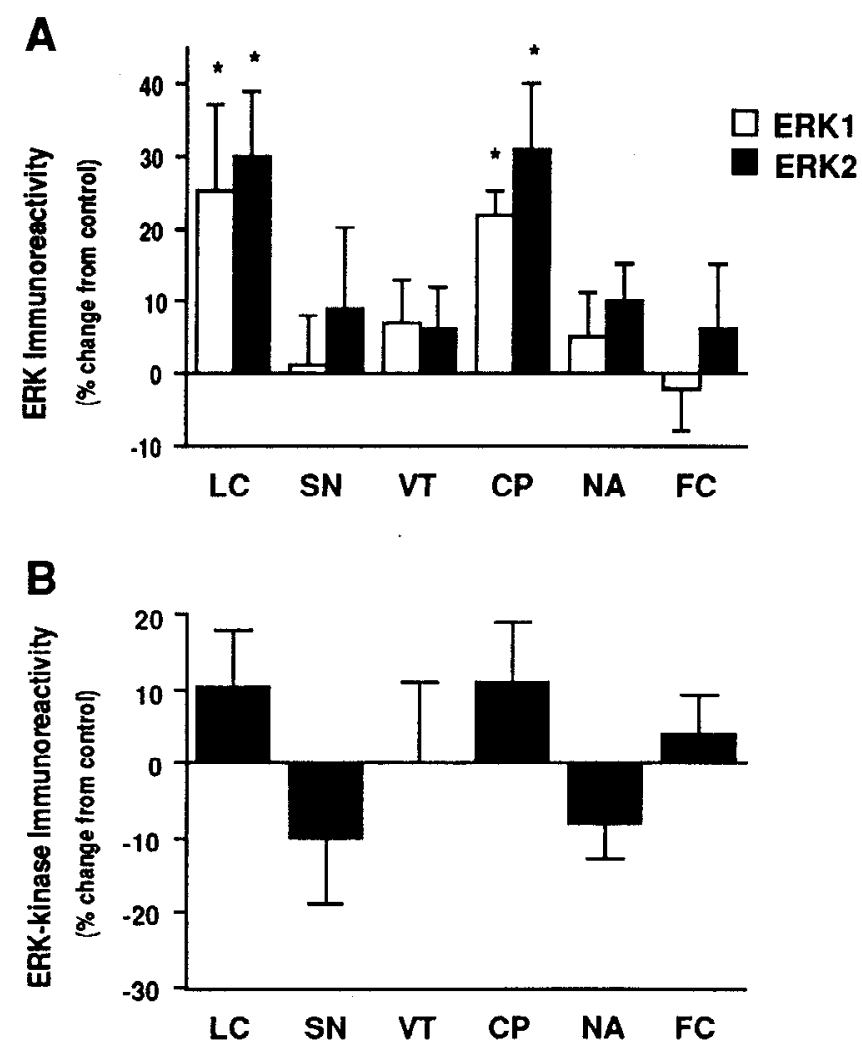

Figure 9. Regulation of ERK and ERK kinase immunoreactivity in rat brain by chronic morphine treatment. Rats were treated chronically with morphine, after which ERK $(A)$ and ERK kinase $(B)$ levels were determined by blot immunolabeling in selected brain regions as described in the captions to Figures 2 and 7. Levels of ERK and ERK kinase immunoreactivity in morphine-treated rats were compared to those in control rats. Data are expressed as mean percentage change from control $\pm S E M$. The results were derived from the following numbers of morphine-treated and control rats; for ERK: $L C, 18 ; S N, 12$; $V T, 12 ; C P, 12 ; N A, 12 ; F C, 12$; for ERK-kinase: $L C, 12 ; S N, 12 ; V T$, $6 ; C P, 12 ; N A, 6 ; F C, 6 .^{*}, p<0.05$ by $\chi^{2}$ test.

bution of the two forms of ERK cannot be explained solely on the basis of a rostral-caudal gradient in the relative amount of white matter in the tissues analyzed: the ERK1-to-ERK2 ratio in forebrain white matter approximated that in frontal cortex, whereas the ratio in pontine white matter approximated that in pons/medulla. Thus, there appeared to be a systematic gradient in the relative expression of ERK 1 versus ERK2 associated with the rostral-caudal location within the neuraxis.

Although attempts were made to examine the regional distribution of ERK3, a third form of ERK found in some cultured cells and animal tissues (Boulton and Cobb, 1991; Wang and Erikson, 1992), blot immunolabeling analysis with commercially available antibodies to ERK3 failed to produce detectable immunoreactivity in any of the brain regions examined (data not shown). An immunoreactive protein of $45 \mathrm{kDa}$, migrating just above ERK 1 was, however, observed in pons/medulla using a mixture of anti-ERK antibodies (see Fig. $6 A$ ). This protein could correspond to ERK4, an additional form of ERK seen in studies of cultured cells but not yet cloned or purified (Boulton and Cobb, 1991). If this identity proves to be correct, the present results would suggest that there is considerable enrichment of ERK4 in pons/medulla relative to forebrain regions.

In a recent report, Thomas and Hunt (1993) studied the re- gional localization of ERK1 and ERK2 mRNA in rat brain and spinal cord by in situ hybridization. Their results differ from those of the present investigation in several respects. While Thomas and Hunt found widespread distribution of ERK2 mRNA throughout the neuroaxis (in agreement with the present study), they found no rostral-caudal gradient in levels of ERK2 mRNA as we found for ERK2 protein (see Table 1). Moreover, they report that ERK1 mRNA shows a more restricted distribution in the brain, with no mRNA detectable, for example, in caudate/putamen, nucleus accumbens, thalamus, and dorsal raphe, brain regions that contain significant levels of ERK1 protein (see Table 1). The differences between the Thomas and Hunt study and our study could result from differential expression of ERK $m$ RNA versus protein in a given brain region. Such differences between the regional distributions of mRNA versus protein should probably be more of an expectation than a surprise. In addition to the essential differences in cellular targeting of mRNA and protein (particularly in the case of long projection neurons), the metabolic life cycles of mRNAs and their translation products share little overlap beyond the translation process itself. In addition, in situ hybridization analyses are, by their nature, less than fully quantitative. This point is underscored by the Northern blotting data of Boulten et al. (1991), who measured levels of ERK1 and ERK2 mRNA in gross subsections of brain. They found, contrary to the in situ hybridization data of Thomas and Hunt but consistent with our immunolabeling data, that ERK2 mRNA does show a rostralcaudal gradient in expression and that ERK1 is widely distributed in the brain. These considerations underscore the difficulty in assessing the regional distribution of a protein by in situ hybridization alone. Moreover, given that a protein, and not its mRNA, is the functional entity, we would like to emphasize the importance of quantitative blot immunolabeling data in obtaining an accurate picture of the chemical anatomy of neuronal systems.

The present study also provides information concerning the subcellular distribution of ERK1 and ERK2 in the brain. The two forms of the enzyme were predominantly soluble in both frontal cortex and pons/medulla, hence, in regions having very different ERK1 and ERK2 ratios. In both regions, the $\mathrm{P}_{2}$ (crude synaptosomal) fractions contained high levels of ERK1 and ERK2. A major component of the $\mathrm{P}_{2}$ fraction are mitochondria, and more highly purified mitochondrial subfractions of $P_{2}$ were shown to contain barely detectable levels of both forms of ERK. This would suggest a particular enrichment of ERK in the nonmitochondrial portion of $\mathrm{P}_{2}$, for example, synaptic elements. Cytosolic fractions also contained high levels of ERK1 and ERK2, whereas the $\mathrm{P}_{3}$ (crude microsomal) fractions contained high levels of ERK2 only. Although identification of the precise subcellular organelle(s) responsible for the enrichment of ERK2 in $\mathrm{P}_{3}$ requires further analysis, this observation does provide one of the first picces of evidence for a differential processing/targeting of ERK1 versus ERK2 in cells.

The $P_{1}$ (crude nuclear) fractions contained lower concentrations of ERK1 and ERK2 than total homogenates, and subfractionated, purified nuclear preparations contained still lower levels of the two forms of ERK. Moreover, an acute electroconvulsive seizure, known to produce ERK phosphorylation and activation in the hippocampus (Baraban et al., 1993), did not increase levels of ERK1 or ERK2 in purified nuclear fractions of this brain region. In addition, ERK immunoreactivity was not detectable in cell nuclei of the hippocampus under resting or sei- 
zure conditions as determined by immunohistochemistry. Although leakage from nuclei during tissue processing cannot be excluded, all of these results converge on the conclusion that appreciable levels of the ERKs are not associated with nuclei in the brain under basal or stimulated conditions. Similarly, in a recent immunohistochemical study of ERK2 (Fiore et al., 1993a), no significant immunoreactivity in HP neuronal nuclei was evident under basal conditions. This is somewhat surprising based on studies of cultured cells, wherein significant nuclear levels of ERK have been demonstrated and an important role for ERKs in the regulation of gene expression has been intimated (e.g., see Boulton et al., 1990; Pulverer et al., 1991; Chen et al., 1992; Gille et al., 1992; Seth et al., 1992; Nakajima et al., 1993). Although it is possible that the low levels of ERKs associated with brain nuclei may be sufficient to effect phosphorylation of transcription factors, the apparent absence of an activationdependent translocation of ERK to the nucleus in brain may indicate that the ERK translocation commonly observed in cultured cells subserves mitogenic aspects of ERK signaling that are suppressed in $\mathrm{G}_{0}$-arrested neurons.

Our regional analyses of ERK activity and phosphotyrosine content revealed that hippocampus contained dramatically higher levels than frontal cortex, nucleus accumbens, caudate/putamen, or pons/medulla, even though the levels of ERK protein in hippocampus were intermediate (Table 1). Moreover, the levels of ERK kinase - which is responsible for phosphorylating and activating ERK in cultured cells - were comparable in hippocampus, nucleus accumbens, and caudate/putamen. Thus, it seems likely that other factors underlie the clcvatcd ERK activity and phosphotyrosine content in hippocampus. One possibility is that other forms of ERK kinase, not recognized by the antibodies used in the present study, are present in the hippocampus at high levels. For example, multiple ERK kinases have already been identified (see Seger et al., 1992; Otsu et al., 1993; Wu et al., 1993), and the number of additional members in this kinase family is presently unknown. Alternatively, we did not determine the regional distribution of ERK kinase $a c$ tivity, and it is possible that the basal level of ERK kinase activity is also elevated in the hippocampus. We did attempt to compare regional levels of upstream activators of ERK kinase (e.g., Raf). However, we were unable to detect Raf immunoreactivity in blot immunolabeling studies of brain regions using commercial antibodies (unpublished observations). Thus, blot immunolabeling studies of other molecules in the ERK-related signaling pathways may have to await devclopment of more suitable immunochemical reagents.

The antibodies to ERK and ERK kinase used in the blot immunolabeling studies were also used successfully for immunohistochemical analyses of brain sections (see Fig. 8). Immunolabeling by the ERK and the ERK kinase antibodies was associated predominantly with neuropil in each of the brain regions analyzed. In the hippocampus, ERK-like and ERK kinase-like immunoreactivities displayed similar laminar distributions. Furthermore, pars reticulata of the substantia nigra exhibited relatively high intensities of immunoreactivity with antibodies to either protein, whereas much lower intensities were observed in the neighboring ventral tegmental area. Overall, the cellular distribution of ERK immunoreactivity observed in the present immunohistochemical studies was similar to that reported recently for ERK2 immunostaining in rat brain (Fiore et al., 1993a), although, in contrast to the present results, these authors reported prominant immunoreactivity associated with cell bodies/dendrites in superficial layers of the cerebral cortex and in the dentate and CA3 cell layers of the hippocampus. Interestingly, based on immunoelectron microscopic data, the dense cell body and dendritic staining of ERK2 seen by Fiore et al. (1993) appeared to be associated with Golgi and microtubules, respectively; this could form the basis for the selective enrichment of ERK2 in microsomal $\left(\mathrm{P}_{3}\right)$ fractions seen in the present study. The absence of prominent cell body/dendritic staining in the present study seems likely to be accounted for by differences in the antibodies and fixation conditions used. Fiore et al. (1993) used antibodies that recognized ERK2 in preference to ERK1, whereas the 691 and 837 antibodies used in the present study recognize both ERK1 and ERK2 with, if any, a slight preference for ERK1 under certain conditions. Also, Fiore et al. used fixative containing $0.15 \%$ glutaraldehyde in addition to $4 \%$ formaldehyde, which may have enhanced retention of ERK2 by microtubules while improving morphological definition.

The catalytic activity of the ERKs and of ERK kinase is strictly dependent upon their phosphorylation, which is regulated on a short-term basis by signaling pathways that are activated by extracellular signal/receptor interactions. However, little attention has been paid to processes involved in the longerterm control of the expression of these proteins or to the possibility that these processes may be subject to physiological or pharmacological regulation. As an initial step in addressing this possibility, we studied the effect of chronic morphine administration on ERK and ERK kinase immunoreactivity in selected brain arcas. Morphine was chosen for this purpose, becausc increasing evidence indicates that the drug alters the levels of several specific signal transduction proteins in the brain after long-term administration (see Nestler, 1992; Nestler et al., 1993). It was found that chronic morphine treatment increases levels of ERK1 and ERK2 in the locus coeruleus and caudate/putamen, but not in several other brain regions examined. Chronic morphine treatment had no effect on levels of ERK kinase immunoreactivity in all of the brain regions studied. The morphine-induced increase in ERK levels in the locus coeruleus is interesting, given the prior evidence that chronic morphine administration also increases levels of cAMP-dependent protein kinase and other components of the cAMP pathway in this brain region. These adaptations in the cAMP pathway have been shown to contribute to the electrophysiological tolerance and dependence that morphine induces in this brain region (Kogan et al., 1992; Nestler, 1992; Nestler et al., 1993). Chronic morphine treatment also increases the expression of tyrosine hydroxylase in the locus coeruleus (Guitart et al., 1990). Given that this enzyme is phosphorylated on a specific serine residue (serine31) by the ERKs (Haycock et al., 1992; Haycock, 1993a), it is possible that the morphine-induced increase in ERK levels provides an additional way in which tyrosine hydroxylase is regulated under morphine-treated conditions. Of course, understanding the full functional significance of morphine regulation of ERKs in the locus coeruleus, as well as in the caudate/putamen, must await information concerning the precise physiological roles played the enzyme in these brain regions under normal conditions.

The present evidence for region-specific distribution of ERKs and ERK kinase in the brain, as well as the enrichment of the ERKs in synaptic fractions of brain and their regulation by chronic morphine administration in specific brain regions, suggest an important role for these enzymes in brain signal trans- 
duction. A major goal of future studies will be to better understand the physiological stimuli that regulate ERK and ERK kinase activity and to identify cellular proteins and processes in the brain controlled by the ERK intraccllular messenger pathway.

\section{References}

Alessi DR, Smythe C, Keyse SM (1993) The human CLl00 gene encodes a Tyr/Thr-protein phosphatase which potently and specifically inactivates MAP kinase and suppresses its activation by oncogenic rats in Xenopus oocyte extracts. Oncogene 8:2015-2020.

Bading H, Greenberg ME (1991) Stimulation of protein tyrosine phosphorylation by NMDA receptor activation. Science 253:912-914.

Baraban J, Fiore RS, Sanghera JS, Paddon HB, Pelech SL (1993) Identification of $\mathrm{p} 42$ mitogen-activated protein kinase as a tyrosine substrate activated by maximal electroconvulsive shock in hippocampus. J Neurochem 60:330-336.

Beitner-Johnson D, Guitart X, Nestler EJ (1992) Neurofilament proteins and mesolimbic dopamine system: common regulation by chronic morphine and chronic cocaine in the rat ventral tegmental arca. $J$ Neurosci 12:2165-2176.

Blenis J (1993) Signal transduction via the MAP kinases: proceed at your own RSK. Proc Natl Acad Sci USA 74:215-217.

Boulton TG, Cobb MH (1991) Identification of multiple extracellular signal-regulated kinases (ERKs) with antipeptide antibodies. Cell Regul 2:357-371.

Boulton TG, Yancopoulos GD, Gregory JS, Slaughter C, Moomaw C, Hsu J, Cobb MH (1990) An insulin-stimulated protein kinase similar to yeast kinases involved in cell cycle control. Science 249:6467.

Boulton TG, Nye SE, Robbins DJ, Ip NY, Radziejewska E, Morgenbesser SD, DePinho RA, Panayotatos N, Cobb MH, Yancopoulos GD (1991) ERKs: a family of protein-serine/threonine kinases that are activated and tyrosine phosphorylated in response to insulin and NGF. Cell 65:663-675.

Cahill AL, Perlman RL (1991) Activation of a microtubule-associated proteins- 2 kinase by insulin-like growth factor-I in bovine chromaffin cells. J Neurochem 57:1832-1839.

Chen R-H, Sarnecki C, Blenis J (1992) Nuclear localization and regulation of erk- and rsk-encoded proteins. Mol Cell Biol 12:915-927.

Cobb MH, Boulton TG, Robbins DJ (1991) Extracellular signal-regulated kinases: ERKs in progress. Cell Regul 2:965-978.

Cotman CW, Banker G, Churchill L, Taylor D (1974) Isolation of postsynaptic densities from rat brain. J Cell Biol 63:441-455.

Crews CM, Erikson RL (1992) Purification of a murine protein-tyrosine/threonine kinase that phosphorylates and activates the Erk-1 gene product: relationship to the fission yeast byrl gene product. Proc Natl Acad Sci USA 89:8205-8209.

Crews CM, Erikson RL (1993) Extracellular signals and reversible protein phosphorylation: what to Mek of it all. Cell 74:215-217.

Crews CM, Alessandrini A, Erikson RL (1992) The primary structure of MEK, a protein kinase that phosphorylates the ERK gene product. Science 258:478-480.

Davis RJ (1993) The mitogen-activated protein kinase signal transduction pathway. J Biol Chem 268:14553-14556.

Dent P, Haser W, Haystead TAJ, Vincent LA, Roherts TM, Sturgill TW (1992) Activation of mitogen-activated protein kinase kinase by v-raf in NIH 3T3 cells and in vitro. Science 257:1404-1407.

Ely CM, Oddie KM, Litz JS, Rossomando AJ, Kanner SB, Sturgill TW, Parsons SJ (1990) A 42-kD tyrosine kinase substrate linked to chromaffin cell secretion exhibits an associated MAP kinase activity and is highly related to a $42-\mathrm{kD}$ mitogen-stimulated protein in fibroblasts. J Cell Biol 110:731-742.

Fiore RS, Bayer VE, Pelech SL, Posada J, Cooper JA, Baraban JM (1993a) p42 mitogen-activated protein kinase in brain: prominent localization in neuronal cell bodies and dendrites. Neuroscience 55: 463-472.

Fiore RS, Murphy TH, Sanghera JS, Pelech SL, Baraban JM (1993b) Activation of $\mathrm{p} 42$ mitogen-activated protein kinase by glutamate receptor stimulation in rat primary cortical cultures. J Neurochem 61 : 1626-1633.

Gille H, Sharrocks AD, Shaw PE (1992) Phosphorylation of transcription factor p62 $2^{\mathrm{TCF}}$ by MAP kinase stimulates ternary complex formation at c-fos promoter. Nature 358:414-417.
Giuffrida AM, Cox D, Mathias AP (1975) RNA polymerase activity in various classes of nuclei from different regions of rat brain during postnatal development. J Neurochem 24:749-755.

Gomez N, Traverse S, Cohen P (1992) Identification of a MAP kinase kinase kinase in phaeochromocytoma (PC12) cells. FEBS Lett 314 $461-465$.

Gotoh Y, Nishida E, Yamashita T, Hoshi M, Kawakami M, Sakai H (1990) Microtubule-associated-protein (MAP) kinase activated by nerve growth factor and epidermal growth factor in PC12 cellsidentity with the mitogen-activated MAP kinase of fibroblastic cells. Eur J Biochem 193:661-669.

Guitart X, Hayward M, Nisenbaum LK, Beitner DB, Haycock JW, Nestler EJ (1990) Identification of MARPP-58, a morphinc- and cyclic AMP-regulated phosphoprotein of $58 \mathrm{kD}$, as tyrosine hydroxylase: evidence for regulation of its expression by chronic morphine in the rat locus coeruleus. J Neurosci 10:2635-2645.

Haycock JW (1990) Phosphorylation of tyrosine hydroxylase in situ at serine 8, 19,31, and 40. J Biol Chem 265:11682-11691.

Haycock JW (1993a) Multiple signaling pathways in bovine chromaffin cells regulate tyrosine hydroxylase phosphorylation at Ser 19 , Ser31 and Ser40. Neurochem Res 18:15-26.

Haycock JW (1993b) Polyvinylpyrrolidone as a blocking agent in immunochemical studies. Anal Biochem 208:397-399.

Haycock JW, Haycock DA (1991) Tyrosine hydroxylase in rat brain dopaminergic nerve terminals: multiple-site phosphorylation in vivo and in synaptosomes. J Biol Chem 266:5650-5657.

Haycock JW, $\Lambda$ hn NG, Cobb MH, Krebs EG (1992) ERK1 and ERK2, two microtubule-associated protein 2 kinases, mediate the phosphorylation of tyrosine hydroxylase at serine-31 in situ. Proc Natl Acad Sci USA 89:2365-2369.

Howe LR, Leevers SJ, Gomez N, Nakielny S, Cohen P, Marshall CJ (1992) Activation of the MAP kinase pathway by the protein kinase raf. Cell 71:335-342.

Hsu SM, Raine L, Fanger $H$ (1981) The use of avidin-biotin peroxidase complex $(\mathrm{ABC})$ in immunoperoxidase techniques: a comparison between $\mathrm{ABC}$ and unlabeled antibody (PAP) procedures. J Histochem Cytochem 29:577-583.

Kogan JH, Nestler EJ, Aghajanian GK (1992) Elevated basal firing rates of locus coeruleus neurons in brain slices from opiate-dependent rats: association with enhanced responses to 8-Br-cAMP. Eur J Pharmacol 211:47-53.

Kyriakis JM, App H, Zhang X-F, Banerjee P, Brautigan DL, Rapp UR, Avruch J (1992) Raf-1 activates MAP kinase-kinase. Nature 358: $417-421$.

Laemmli UK (1970) Cleavage of structural proteins during the assembly of the head of bacteriophage T4. Nature 227:680-682.

Lange-Carter CA, Pleiman CM, Gardner AM, Blumer KJ, Johnson GL (1993) A divergence in the MAP kinase regulatory network defined by MEK kinase and Raf. Science 260:315-319.

Lloyd ED, Wooten MW (1992) pp42/44MAP kinase is a component of the neurogenic pathway utilized by nerve growth factor in PC12 cells. J Neurochem 59:1099-1109.

Lowry OH, Rosebrough MJ, Farr AL, Randall RJ (1951) Protein measurement with the Folin phenol reagent. J Biol Chem 193:265275.

Matsuda S, Gotoh Y, Nishida E (1993) Phosphorylation of Xenopus mitogen-activated protein (MAP) kinase kinase by MAP kinase kinase kinase and MAP kinase. J Biol Chem 268:3277-3281.

Nakajima T, Kinoshita S, Sasagawa T, Sasaki K, Naruto M, Kishimoto T, Akira S (1993) Phosphorylation at threonine-235 by a ras-dependent mitogen-activated protein kinase cascade is essential for transcription factor NF-IL6. Proc Natl Acad Sci USA 90:2207-2211.

Nestler EJ (1992) Molecular mechanisms of drug addiction. J Neurosci $12: 2439-2450$

Nestler EJ, Terwilliger RZ, Duman RS (1989) Chronic antidepressant administration alters the subcellular distribution of cyclic AMP-dependent protein kinase in rat frontal cortex. J Neurochem 53:16441647.

Nestler EJ, Hope BT, Widnell KL (1993) Drug addiction: a model for the molecular basis of neural plasticity. Neuron 11:995-1006.

Nishida E, Gotoh Y (1993) The MAP kinase cascade is essential for diverse signal transduction pathways. Trends Biochem Sci 18:118121.

Otsu M, Terada Y, Okayama H (1993) Isolation of two members of the rat MAP kinase kinase gene family. FEBS Lett 320:236-250. 
Pages G, Lenormand P, L'Allemain G, Chambard J-C, Meloche S, Pouyssegur J (1993) Mitogen-activated protein kinases p42 ${ }^{\text {mapk }}$ and p44mapk are required for fibroblast proliferation. Proc Natl Acad Sci USA 90:8319-8323.

Pavlovic-Surjancev B, Cahill AL, Perlman RL (1992) Nicotinic agonists, phorbol esters and growth factors activate two extracellular signal-regulated kinases, ERK 1 and ERK2, in bovine chromaffin cells. J Neurochem 59:2134-2140.

Pelech SL (1993) Signal transduction: networking with protein kinases. Curr Biol 3:513-515.

Posoda J, Yew N, Ahn NG, Vande Woude GF, Cooper JA (1993) Mos stimulates MAP kinase in Xenopus oocytes and activates a MAP kinase kinase in vitro. Mol Cell Biol 13:2546-2553.

Pulverer BJ, Kyriakis JM, Avruch J, Nikolakaki E, Woodgett JR (1991) Phosphorylation of c-jun mediated by MAP kinases. Nature 353:670674.

Qiu M-S, Green SH (1992) PC12 cell neuronal differentiation is associated with prolonged $\mathrm{p} 21^{\text {ras }}$ activity and consequent prolonged ERK activity. Neuron 9:705-717.

Rasmussen K, Beitner-Johnson D, Krystal JH, Aghajanian GK, Nestler FJ (1990) Opiate withdrawal and the rat locus coeruleus: behavioral, electrophysiological, and biochemical correlates. J Neurosci 10:23082317.

Robbins DJ, Zhen E, Owaki H, Vanderbilt CA, Ebert D, Geppert TD, Cobb MH (1993) Regulation and properties of extracellular signalregulated protein kinases 1 and 2 in vitro. J Biol Chem 268:50975106.

Rossomando AJ, Payne DM, Weber MJ, Sturgill TW (1989) Evidence that $\mathrm{pp} 42$, a major tyrosine kinase substrate, is a mitogen-activated serine/threonine protein kinase. Proc Natl Acad Sci USA 86:69406943.

Rossomando A, Wu J, Weber MJ, Sturgill TW (1992) The phorbol ester-dependent activator of the mitogen-activated protein kinase p42mapk is a kinase with specificity for the threonine and tyrosine regulatory sites. Proc Natl Acad Sci USA 89:5221-5225.

Schanen NC, Landreth G (1992) Isolation and characterization of microtubule-associated protein 2 (MAP2) kinase from rat brain. Mol Brain Res 14:43-50.
Scimeca J-C, Nguyen TT, Filloux C, Van Obberghen E (1992) Nerve growth factor-induced phosphorylation cascade in PC12 phenochromocytoma cells. Association of S6 kinase II with the microtubuleassociated protein kinase, ERK1. J Biol Chem 267:17369-17374.

Seger R, Seger D, Lozeman FJ, Ahn NG, Graves LM, Campbell JS, Ericsson L, Harrylock M, Jensen AM, Krebs EG (1992) Human T-cell mitogen-activated protein kinase kinases are related to yeast signal transduction kinases. J Biol Chem 267:25628-25631.

Seth A, Gonzalez FA, Gupta S, Raden DL, Davis RJ (1992) Signal transduction within the nucleus by mitogen-activated protein kinase. J Biol Chem 267:24796-24804.

Stratton KR, Worley PF, Litz JS, Parsons SJ, Huganir RL, Baraban JM (1991) Electroconvulsive treatment induces a rapid and transient increase in tyrosine phosphorylation of a 40-kilodalton protein associated with microtubule-associated protein 2 kinase activity. J Neurochem 56:147-152.

Thomas KL, Hunt SP (1993) The regional distribution of extracellularly regulated kinase- 1 and-2 messenger RNA in the adult rat central nervous system. Neuroscience 56:741-757.

Traverse S, Gomez N, Paterson H, Marshall C, Cohen P (1992) Sustained activation of the mitogen-activated protein (MAP) kinase cascade may be required for differentiation of $\mathrm{PC} 12$ cells. Comparison of the effects of nerve growth factor and epidermal growth factor. Biochem J 288:351-355.

Tucker MS, Eves EM, Wainer BH, Rosner MR (1993) Activation of mitogen-activated protein kinase by epidermal growth factor in hippocampal neurons and neuronal cell lines. J Neurochem 61:13761387.

Wang H-CR, Erikson RL (1992) Activation of protein serine/threonine kinases $p 42, p 63$, and $p 87$ in rous sarcoma virus-transformed cells: signal transduction/transformation-dependent MBP kinases. Mol Biol Cell 3:1329-1337.

Wu J, Harrison JK, Dent P, Lynch KR, Weber MJ, Sturgill TW (1993) Identification and characterization of a new mammalian mitogenactivated protein kinase kinase, MKK2. Mol Cell Biol 13:4539-4548.

Zheng C-F, Guan K-L (1933) Dephosphorylation and inactivation of the mitogen-activated protein kinase by a mitogen-induced $\mathrm{Thr} / \mathrm{Tyr}$ protein phosphatase. J Biol Chem 268:16116-16119. 